\title{
Effect of Plasma-membrane Phospholipid Unsaturation on Solute Transport into Saccharomyces cerevisiae NCYC 366
}

\author{
By MICHAEL H. J. KEENAN ${ }^{1}$, ANTHONYH. ROSE ${ }^{*}$ AND \\ BERNARD W. SILVERMAN ${ }^{2}$ \\ ${ }^{1}$ Zymology Laboratory, School of Biological Sciences and ${ }^{2}$ School of Mathematics, University of \\ Bath, Bath BA2 7AY, Avon, U.K.
}

(Received 15 January 1982; revised 6 April 1982)

A comparison was made of kinetics of solute accumulation by Saccharomyces cerevisiae NCYC 366 grown anaerobically under conditions that lead to enrichment of the plasma membrane with ergosterol and either oleyl or linoleyl residues. Values for $K_{\mathrm{T}}$ and $V_{\max }$ were identical for accumulation of $\mathrm{L}$-asparagine, $\mathrm{L}$-glutamine, $\mathrm{H}_{2} \mathrm{PO}_{4}^{-}, \mathrm{Ca}^{2+}$ and $\mathrm{SO}_{4}^{2-}$, while for accumulation of D-glucose, the value differed slightly but not significantly. Values for $K_{\mathrm{T}}$ for accumulation of L-lysine, by both the low- and high-affinity systems, decreased when oleyl residues were replaced by linoleyl residues. Under these conditions, $V_{\max }$ values for the high-affinity system decreased while that for the low-affinity system increased. An Arrhenius plot for accumulation of lysine by the high-affinity system revealed a discontinuity when membranes were enriched in linoleyl residues. However, no discontinuity was evident on plots of lysine accumulation when membranes were enriched in oleyl residues. Similar plots for accumulation of $\mathrm{L}$-asparagine, which was used as a control, showed that substitution of linoleyl for oleyl residues significantly raised the transition temperature, but had little effect on the activation energy at temperatures below the discontinuity. When palmitoleyl residues were incorporated into the yeast plasma membrane, the $K_{\mathrm{T}}$ value for L-lysine accumulation by the high-affinity system was hardly altered, although the $V_{\max }$ value was lowered, as compared with organisms with membranes enriched in oleyl residues. Replacement of oleyl by palmitoleyl residues lowered both the $K_{\mathrm{T}}$ and $V_{\max }$ values for accumulation of L-asparagine. A modified statistical method is described for calculating confidence limits for transition points on Arrhenius plots.

\section{INTRODUCTION}

The activities of several microbial plasma-membrane-bound proteins are influenced by lipids (Sanderman, 1978). The majority of these effects have been demonstrated in bacteria, and include interactions involving proteins that catalyse synthesis of wall components (Inouye, 1974; Gennis \& Strominger, 1976; Hinckley et al., 1972) and proteins involved in energygenerating metabolism (Cunningham \& Hager, 1971; Peter \& Ahlers, 1975; Salton \& Schor, 1974; Aiyappa \& Lampen, 1976; Bevers et al., 1977). Reports on the effects of lipids on transport of molecules across the bacterial plasma membrane are less numerous. Beepe (1972) found that a mutant of Bacillus subtilis unable to synthesize phosphatidylethanolamine differed from the parent in its rate of uptake of several solutes, including eight amino acids, while Cox et al. (1975), using a fatty acid-requiring auxotroph of Escherichia coli, showed that the rate of transport of several amino acids by organisms enriched in $c i s$-vaccenyl residues was slower than with organisms enriched in oleyl or palmitoleyl residues. Far fewer studies have been reported on the effect of plasma-membrane lipid composition on protein activity in eukaryotic micro-organisms (Sanderman, 1978). Phosphatidylcholine has, however, been implicated in L-lysine uptake by Neurospora crassa, since a phosphatidylcholine-deficient mutant had a decreased capacity for accumulating this amino acid (Sherr, 1969), while activity of one of the glucose-transporting 
systems in another strain of this fungus decreased when it was grown under conditions of inositol deprivation, thereby suggesting a role for phosphatidylinositol in transport (Scarborough, 1973). A recent report indicated that the plasma-membrane ATPase in Schizosaccharomyces pombe, which is involved in formation of the proton gradient used in active uptake of solutes, requires phospholipids for activity (Dufour \& Goffeau, 1980).

The present paper reports on the effect of the fatty-acyl composition of plasma-membrane phospholipids on accumulation of solutes by Saccharomyces cerevisiae NCYC 366. The study exploits a nutritional technique for changing the lipid composition of the plasma membrane, namely the anaerobically-induced requirement in $S$. cerevisiae for a sterol and an unsaturated fatty acid (Andreasen \& Stier, 1953, 1954). Both of these nutritional requirements are fairly broad (Light et al., 1962; Proudlock et al., 1968) and this permits specific enrichments to be made in the sterol (Hossack \& Rose, 1976) and fatty-acyl composition of plasma membranes (Thomas et al., 1978) without altering the content and composition of other types of lipid in organisms (Rose, 1977).

\section{METHODS}

Experimental cultures. Saccharomyces cerevisiae NCYC 366 was maintained on slopes of malt extract/yeast extract/glucose/peptone/agar medium (Wickerham, 1951). The yeast was grown anaerobically as described by Alterthum \& Rose (1973) with the medium (pH 4.5) supplemented with ergosterol (5 $\left.\mathrm{mg} \mathrm{l}^{-1}\right)$ and an unsaturated fatty acid $\left(30 \mathrm{mg} \mathrm{l}^{-1}\right)$ as indicated in the text. Growth was followed by measuring turbidity at $600 \mathrm{~nm}$, and organisms were harvested from late-exponential phase cultures $\left(0.24-0.26 \mathrm{mg} \mathrm{dry} \mathrm{wt} \mathrm{ml}{ }^{-1}\right)$ by filtration through a membrane filter $(0.45 \mu \mathrm{m}$ pore size, $50 \mathrm{~mm}$ diam.; Oxoid). Control cultures lacking ergosterol were incubated with each batch of experimental cultures and when growth in the control exceeded $0.1 \mathrm{mg}$ dry wt $\mathrm{ml}^{-1}$, experimental cultures were discarded.

Measurement of rate of solute accumulation. Organisms which were to be used to measure the rate of solute accumulation were washed with PIPES buffer $(20 \mathrm{mM})$ adjusted to $\mathrm{pH} 4.5$ (pH 5.5 when uptake of $\mathrm{Ca}^{2+}$ was to be studied), and suspended at $15 \mathrm{mg}$ dry wt $\mathrm{ml}^{-1}$ in the same buffer in a screw-capped centrifuge tube $(250 \mathrm{ml})$. The tube was stored in an ice-water mixture after the headspace had been flushed with oxygen-free nitrogen gas. The suspension $(15 \mathrm{ml})$ used to measure the rate of solute accumulation consisted of PIPES buffer ( $\mathrm{pH} 4.5$ or 5.5 ) containing glucose (100 mM) (except when the rate of uptake of D-glucose was to be measured), $0.5 \mathrm{mg}$ dry wt organisms $\mathrm{ml}^{-1}$ and solute in the range $10^{-6}-10^{-1} \mathrm{M}$, including both radioactive and non-radioactive compounds. The concentrations of radioactive compounds in the solute solutions used were $\left(\mu \mathrm{Ci} \mu \mathrm{mol}^{-1} ; 1 \mu \mathrm{Ci}=37 \mathrm{kBq}\right): \mathrm{L}-$ $\left[\mathrm{U}-{ }^{14} \mathrm{C}\right]$ arginine monohydrochloride, $0 \cdot 05 ; \mathrm{L}-\left[\mathrm{U}-{ }^{14} \mathrm{C}\right]$ asparagine, $3 \cdot 3 ;{ }^{45} \mathrm{CaCl}_{2}, 12 \cdot 5 ; \mathrm{D}-\left[6-{ }^{3} \mathrm{H}\right] \mathrm{glucose}, 0 \cdot 75-750 ; \mathrm{L}-$ [U- ${ }^{14} \mathrm{C}$ ]glutamine, $3 \cdot 3 ; \mathrm{L}-\left[\mathrm{U}-{ }^{14} \mathrm{C}\right]$ lysine monohydrochloride, $0 \cdot 013-1 \cdot 67 ; \mathrm{KH}_{2}{ }^{32} \mathrm{PO}_{4}, 2 \cdot 0$; and $\mathrm{Na}_{2}{ }^{35} \mathrm{SO}_{4}, 0.03-30$. Where ranges are indicated, the tracer:carrier ratio was varied because of wide differences in the rate of accumulation at different solute concentrations. The suspension was contained in a round bottomed Quickfit flask (100 ml capacity) fitted with a glass-stoppered sampling port. When preparing the suspension, the flask was maintained in a water-bath at $30^{\circ} \mathrm{C}$ except when otherwise stated. Its contents were stirred magnetically, and the inside of the flask continuously flushed with oxygen-free nitrogen gas. The experiment was started by adding solute (tracer and carrier) to the flask, after which portions $(1 \mathrm{ml})$ were removed at predetermined times, rapidly filtered through membrane filters ( $0.45 \mu \mathrm{m}$ pore size, $25 \mathrm{~mm}$ diam.; Millipore) and the filter and cells immediately washed with ice-cold PIPES buffer ( $\mathrm{pH} 4.5$ or 5.5) containing the solute at the concentration included in the cell suspension. Filters were then transferred to scintillation vials containing $7 \mathrm{ml}$ Unisolve liquid scintillator no. 1 (Koch-Light). The radioactivity of the vial contents was measured in a Packard Tricarb liquid scintillation spectrometer (model 3385), and the values corrected for counting efficiency. Rates of accumulation were determined from plots of the time-course of accumulation for up to $195 \mathrm{~s}$, although linear plots were obtained with low concentrations of solute for up to $30 \mathrm{~min}$. Woolf-Hofstee plots (Hofstee, 1959) were used to calculate $K_{\mathrm{T}}$ and $V_{\max }$ values for uptake systems.

The fate following accumulation of one of the solutes examined, $\mathrm{L}-\left[\mathrm{U}-{ }^{14} \mathrm{C}\right]$ arginine, was followed by examining hot-water extracts of organisms and cell debris for ${ }^{14} \mathrm{C}$-containing compounds. Organisms were removed from suspensions as already described, and filters with organisms immersed in $10 \mathrm{ml}$ water at $100^{\circ} \mathrm{C}$ for $10 \mathrm{~min}$. The suspension was then filtered through a membrane filter $(0.45 \mu \mathrm{m}$ pore size, $25 \mathrm{~mm}$ diam.; Millipore $)$ and the radioactivity of the filtrate measured. The debris was then washed with arginine $(200 \mu \mathrm{M})$, the filter with washed debris transferred to a scintillation vial and the radioactivity of the contents measured. Ninhydrin-positive compounds in the filtrate were separated by paper chromatography using the following solvent systems: ethanol/ water/urea $(80: 20: 0 \cdot 5, \mathrm{v} / \mathrm{v} / \mathrm{w})$, butanol/pyridine/water $(315: 175: 240$, by vol. $)$ and $\mathrm{phenol} / \mathrm{water} / 25 \%(\mathrm{v} / \mathrm{v})$ aqueous ammonia (sp.gr. 0.88$)(80: 20: 0 \cdot 3, \mathrm{w} / \mathrm{v} / \mathrm{v})$. Chromatograms were dried, sprayed with ninhydrin $(0 \cdot 1 \%$, w/v, in $\mathrm{n}$-butanol saturated with water) and the location of spots marked. They were then exposed to photographic plates 
(Kodak Industrex C) for four weeks. Filtrates from extracts of organisms sampled up to 30 min revealed only one radioactive spot, with an $R_{F}$ value identical with that of arginine in all three solvents. Extracts from organisms incubated for 90 min contained a second radioactive compound which was not identified. Radioactivity was detectable in the debris from organisms incubated for $5 \mathrm{~min}$, although this represented less than $3 \%$ of the total accumulated.

Lipid analysis. Organisms to be used for lipid analysis were washed twice with water on a membrane filter, and lipid was extracted by a modification of the procedures of Folch et al. (1957) and Watson \& Rose (1980). Freshly washed organisms $(1 \mathrm{~g}$ dry $\mathrm{wt})$ were mixed with methanol $(20 \mathrm{ml})$ and the suspension was shaken in a Braun homogenizer (B. Braun, Melsungen, F.R.G.) for three periods of $30 \mathrm{~s}$ at speed 2 (4000 r.p.m.) after addition of $30 \mathrm{~g}$ of glass beads (0.45-0.50 mm diam.; Glasperlen, B. Braun). Chloroform was then added to the suspension to give a ratio of $2: 1(\mathrm{v} / \mathrm{v})$ chloroform/methanol, and the suspension stirred on a flatbed stirrer for $2 \mathrm{~h}$ at room temperature $\left(20-24{ }^{\circ} \mathrm{C}\right)$. The suspension was then filtered through Whatman no. 44 filter paper, and the extraction procedure repeated on the residue. The combined extracts were washed with $0.25 \mathrm{vol} .0 \cdot 88 \%(\mathrm{w} / \mathrm{v}) \mathrm{KCl}$, and the mixture left to separate overnight at $4{ }^{\circ} \mathrm{C}$. The lower phase was removed, taken to dryness on a rotary evaporator, and the residue immediately dissolved in chloroform/methanol $(2: 1, \mathrm{v} / \mathrm{v})$. Samples were stored under nitrogen gas at $-20{ }^{\circ} \mathrm{C}$. Phospholipids were separated from other lipid classes in extracts by TLC on plates of silica gel $\mathrm{H}(0 \cdot 5 \mathrm{~mm}$ thick) using a solvent system of hexane/diethyl ether/acetic acid $(70: 30: 2$, by vol.). Lipid bands were located by exposing plates to iodine vapour, and were marked with pins. The phospholipid band was identified by reference to simultaneously run standards of phosphatidylcholine or phosphatidylethanolamine. Individual phospholipids were separated from extracts by TLC on plates of silica gel $\mathrm{H}(0.5 \mathrm{~mm}$ thick $)$ using a solvent system of chloroform/ methanol/acetic acid/water $(25: 15: 4: 2$, by vol.; Skipski et al., 1964). Using this procedure, phosphatidylinositol and phosphatidylserine were not completely separated, and fatty-acyl compositions were determined for the combined fraction. Saccharomyces cerevisiae NCYC 366 resembles other strains of this species in containing appreciably more phosphatidylinositol than phosphatidylserine (Ratcliffe et al., 1973). Phospholipid spots were located by exposing the plates to iodine vapour. The iodine was allowed to sublime at room temperature; spots of lipid classes or individual phospholipids were scraped off the plates, and fatty acid methyl esters were prepared by refluxing the silica gel with methanol containing $14 \%(\mathrm{w} / \mathrm{v}) \mathrm{BF}_{3}$, for $10 \mathrm{~min}$. After cooling, an equal volume of water was added, and the methyl esters were extracted into chloroform. The same procedure was used to prepare fatty acid methyl esters from neutral-lipid fractions containing sterol esters and di- and triacylglycerols. Fatty acid methyl esters were analysed by GLC on a column $(2 \mathrm{~m})$ of $15 \%$ EGSS-Y supported on 100 to 120 mesh Gas-Chrom $\mathrm{P}$ at $200{ }^{\circ} \mathrm{C}$. The injection port was at $210^{\circ} \mathrm{C}$, and the carrier gas (nitrogen) flow rate was $60 \mathrm{ml} \mathrm{min}^{-1}$. Percentage fatty acid compositions were calculated by multiplying the retention time by the peak height on the trace.

Assay of asparaginase activity. The activity of the cell wall enzyme asparaginase II (Dunlop et al., 1978; Lasparagine amidohydrolase, EC 3.5.1.1), was assayed by following the appearance of L-aspartate in a buffered suspension of organisms containing L-asparagine. Washed organisms were suspended at a density of $15 \mathrm{mg} \mathrm{dry} \mathrm{wt}$ $\mathrm{ml}^{-1}$ in PIPES buffer (pH 4.5) in a Quickfit flask ( $100 \mathrm{ml}$ capacity) and the suspension sparged with oxygen-free nitrogen gas as described for measurement of the rate of solute accumulation. The assay was started by adding $\mathrm{L}$ asparagine to a final concentration of $1 \mathrm{~mm}$. Portions of suspension were removed at intervals and rapidly filtered through membrane filters $(0.45 \mu \mathrm{m}$ pore size, $25 \mathrm{~mm}$ diam.; Oxoid). The concentration of L-aspartate in filtrates was determined spectrophotometrically by coupling with L-glutamate-oxaloacetate transaminase and L-malate dehydrogenase as described by Dunlop \& Roon (1975).

Statistical analysis. Slopes of lines on Arrhenius plots, and points of intersection of these lines, were calculated using the method of Hinkley (1969). Confidence limits for transition points were calculated using a corrected version of Hinkley's method.

Chemicals. All chemicals used were of Analar grade or of the highest purity available commercially. Ergosterol, palmitoleic acid $\left(\Delta^{9}\right.$-cis-hexadecenoic acid), oleic acid ( $\Delta^{9}$-cis-octadecenoic acid), linoleic acid ( $\Delta^{9.12}$-cis,cis-octadecadienoic acid), cetoleic acid ( $\Delta^{11}$-cis-eicosaenoic acid) and PIPES were purchased from Sigma. Radioactively labelled compounds were obtained from Amersham.

\section{RESULTS}

\section{Effect of storage time on solute-accumulating ability of organisms}

The viability of the suspension of organisms maintained in an ice-water mixture prior to use in solute accumulation measurements, as judged by plate counts using the medium of Wickerham (1951), did not change over a period of $5 \mathrm{~h}$. The ability of organisms enriched in oleyl residues to accumulate L-arginine declined only slowly during storage in an ice-water mixture, but after about $\mathbf{l} \mathrm{h}$ the arginine-accumulating ability of organisms enriched in linoleyl residues 


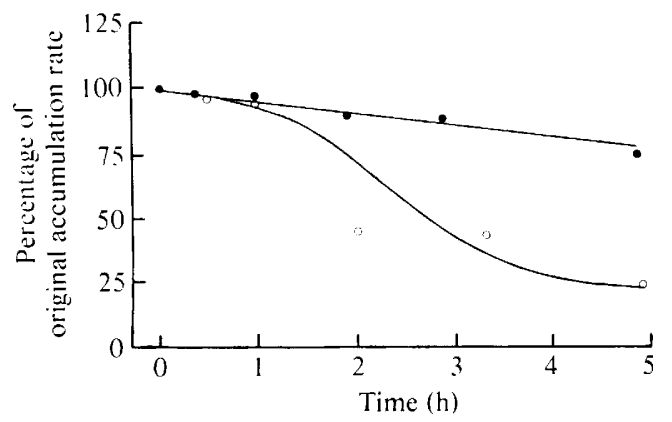

Fig. 1. Effect of storage time on the ability of S. cerevisiae NCYC 366 enriched in oleyl (O) or linoleyl (O) residues to accumulate L-arginine. Organisms were stored in an ice-water mixture in PIPES buffer (pH 4.5) under nitrogen gas. Cell suspensions used for uptake measurements contained $100 \mu \mathrm{M}-\mathrm{L}^{-}$ arginine. Each value represents the average of at least three independent measurements.

declined rapidly (Fig. 1). Comparable observations on the ability of organisms to accumulate other solutes were not made, although it was established that the ability of organisms enriched in either oleyl or linoleyl residues to accumulate any of the other solutes investigated hardly declined over the first hour of storage. All determinations were therefore made on organisms that had been stored in an ice-water mixture for not more than $1 \mathrm{~h}$, and usually for considerably less.

\section{Solute accumulation by organisms enriched in oleyl or linoleyl residues}

Keenan \& Rose (1979) reported that the $K_{\mathrm{T}}$ and $V_{\max }$ values for accumulation of L-arginine in $S$. cerevisiae NCYC 366, by both high- and low-affinity systems, differed in organisms enriched in oleyl as compared with linoleyl residues. A survey was therefore made of the effect of fattyacyl enrichment on the kinetics of accumulation of a representative range of other solutes. Values for $K_{\mathrm{T}}$ and $V_{\max }$ for five of these solutes, namely L-asparagine, L-glutamine, $\mathrm{H}_{2} \mathrm{PO}_{4}^{-}, \mathrm{Ca}^{2+}$ and $\mathrm{SO}_{4}^{2-}$, were identical, irrespective of the nature of the fatty-acyl enrichment. Kinetic values for accumulation of phosphate, calcium and sulphate ions were, moreover, similar to those already reported for these transport systems in strains of $S$. cerevisiae grown aerobically (BorstPauwels \& Jager, 1969; Fuhrmann \& Rothstein, 1968; Breton \& Surdin-Kerjan, 1977). Values for $K_{\mathrm{T}}$ and $V_{\max }$ for accumulation of L-asparagine and L-glutamine, which have not previously been reported for $S$. cerevisiae, were: L-asparagine, $K_{\mathrm{T}} 4 \times 10^{-4} \mathrm{M}, V_{\max } 14 \mathrm{nmol}(\mathrm{mg} \text { dry wt })^{-1}$ $\min ^{-1}$; and L-glutamine, $K_{\mathrm{T}} 3.3 \times 10^{-4} \mathrm{M}, V_{\max } 15 \mathrm{nmol}(\mathrm{mg} \text { dry wt) })^{-1} \mathrm{~min}^{-1}$. Organisms were shown to lack cell wall asparaginase II activity reported in other strains of $S$. cerevisiae by Dunlop \& Roon (1975). Values for $K_{\mathrm{T}}$ for accumulation of D-glucose by organisms enriched in oleyl or linoleyl residues were virtually identical with those already reported for $S$. cerevisiae grown aerobically (Kotyk, 1967), although the $V_{\max }$ values differed slightly, but not significantly [232 $\mathrm{nmol}\left(\mathrm{mg}\right.$ dry wt) ${ }^{-1} \mathrm{~min}^{-1}$ for organisms enriched in oleyl residues, and $266 \mathrm{nmol}(\mathrm{mg}$ dry $\mathrm{wt})^{-1} \mathrm{~min}^{-1}$ for those enriched in linoleyl residues]. Accumulation of L-lysine, like that of Larginine (Keenan \& Rose, 1979), was effected by both high- and low-affinity systems (Fig. 2). The equations derived by Neal (1972) were used to obtain separate $K_{\mathrm{T}}$ and $V_{\max }$ values for each of the uptake systems, with the assumption that both systems are described by MichaelisMenten kinetics. Both kinetic values differed when organisms enriched in either oleyl or linoleyl residues accumulated L-lysine by either the high-affinity or low-affinity system.

\section{Effect of temperature on accumulation of L-lysine and L-asparagine by organisms enriched in oleyl or linoleyl residues}

Further insight into the effect of fatty-acyl unsaturation on L-lysine accumulation was sought by examining the effect of temperature on accumulation by the high-affinity system. For comparison, an examination was made of the effect of temperature on accumulation of L- 


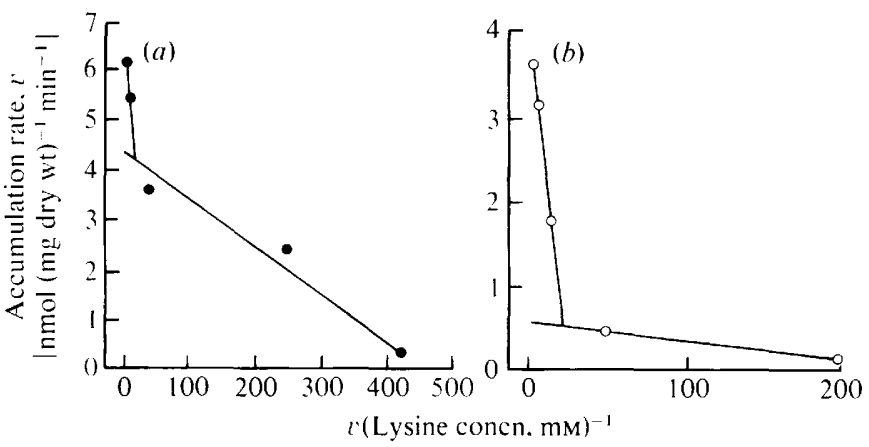

Fig. 2. Woolf-Hof stee plots for accumulation of L-lysine by $S$. cerevisiae NCYC 366 enriched in oleyl residues $(a)$ or linoleyl residues $(b)$. Rates of accumulation were determined as described in Methods. Each value represents the average of at least three independent observations. The lines represent the relationship between points showing the regression coefficient nearest unity. The maximum variation on any one velocity value was $\pm 15 \%$. Values for $K_{\mathrm{T}}(\mathrm{M})$ for the high-affinity system were $6.5 \times 10^{-6}$ for organisms enriched in oleyl residues, and $0.25 \times 10^{-6}$ for organisms enriched in linoleyl residues. Corresponding values for the low-affinity system were $2.8 \times 10^{-4}$ and $1 \cdot 1 \times 10^{-4}$, respectively. Values for $V_{\max }\left[\mathrm{nmol}(\mathrm{mg} \mathrm{dry} \mathrm{wt})^{-1} \mathrm{~min}^{-1}\right]$ for the high-affinity system were $4 \cdot 2$ (organisms enriched in oleyl residues) and 0.5 (organisms enriched in linoleyl residues). Corresponding values for the low-affinity system were 1.9 and $3 \cdot 1$, respectively.

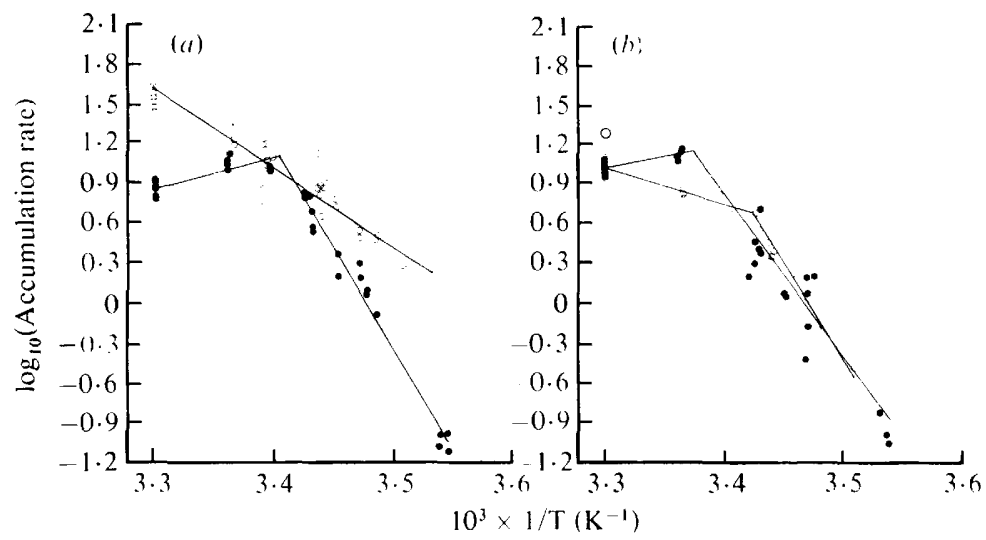

Fig. 3. Arrhenius plots for accumulation of L-lysine (a) and L-asparagine (b) by S. cerevisiae NCYC 366 enriched in oleyl residues $(O)$ or linoleyl residues $(O)$. Cell suspensions contained $10 \mu \mathrm{M}$-amino acid. Each value represents the average of at least two independent measurements. Rates of accumulation were determined as described in Methods. Slopes of lines and transition temperatures were calculated using a corrected version of the method of Hinkley (1969).

asparagine, $K_{\mathrm{T}}$ and $V_{\max }$ values for which were not affected by the change in plasma-membrane fatty-acyl unsaturation, Hinkley's method for statistical analysis of these types of data (Hinkley, 1969) assumes that there is a linear response in each of two regimes, with a change of slope at the point $\gamma$. To the left of $\gamma$ the slope is $\beta_{0}$, to the right, $\beta_{1}$. Application of Hinkley's algorithm (Hinkley, 1969) for finding the least-squares fit of the model for the data yielded point estimates $\widehat{\beta}_{0}, \hat{\beta}_{1}$, and $\hat{\gamma}$ of the parameters in the model. The procedure is complicated, and a FORTRAN program was written to implement it, incorporating also the statistical modifications described below.

Application of the test of Hinkley (1969) for the existence of a transition point showed that, with data for uptake of L-lysine by organisms enriched in oleyl residues, there was no significant change in slope of the Arrhenius plot (Fig. 3). The activation energy was calculated from the 
Table 1. Values for transition temperatures and activation energies derived from Arrhenius plots for accumulation of $\mathrm{L}-l y$ sine and $\mathrm{L}$-asparagine by S. cerevisiae NCYC 366 enriched in oleyl or linoleyl residues

$\begin{array}{lccrr}\text { Amino acid* } & \begin{array}{c}\text { Fatty-acyl } \\ \text { enrichment }\end{array} & \begin{array}{c}\text { Transition temperature } \\ \left({ }^{\circ} \mathrm{C}\right) \dagger\end{array} & \overbrace{\begin{array}{c}\text { Below } \\ \text { transition }\end{array}}^{\begin{array}{c}\text { Activation energy } \\ (\mathrm{kJ} \mathrm{mol}-1) \ddagger\end{array}} \begin{array}{c}\text { Above } \\ \text { transition }\end{array} \\ \text { L-Lysine } & \text { Oleyl } & - & 113 \pm 10 & 113 \pm 10 \\ \text { L-Asparagine } & \text { Linoleyl } & 20 \cdot 5(19 \cdot 8,21 \cdot 2) & 295 \pm 21 & -46 \pm 24 \\ & \text { Oleyl } & 19 \cdot 0(17 \cdot 7,20 \cdot 2) & 285 \pm 40 & 52 \pm 26 \\ & \text { Linoleyl } & 23 \cdot 2(21 \cdot 1,30) & 237 \pm 44 & -32 \pm 64\end{array}$

* Rates of amino acid uptake were measured in suspensions containing the amino acid at $10 \mu \mathrm{M}$.

$\dagger$ Transition temperatures were calculated using the corrected version of the method of Hinkley (1971). Values in parentheses are asymmetrical $95 \%$ confidence limits.

$\ddagger$ Activation energies are quoted \pm two standard errors of the mean.

slope of the line, and confidence limits determined by standard linear regression theory (Table 1). Analysis of the other three Arrhenius plots revealed that each showed a significant change in slope. The method of Hinkley (1969) was then used to calculate point estimates $\hat{\gamma}$ and $\hat{\beta}_{1}$ and approximate $95 \%$ confidence limits for the activation energy $\beta_{1}$. Hinkley's procedure for finding a confidence interval for the transition point was examined and found to be applicable to data for L-lysine accumulation by organisms enriched in linoleyl residues and L-asparagine accumulation by organisms enriched in oleyl residues.

However, data on L-asparagine accumulation by linoleyl-enriched organisms exposed the need for a modification of the method of Hinkley $(1969,1971)$, as follows. Suppose that the distinct abscissae of the data are $u_{1}<u_{2}<\ldots<u_{r}$ (with $\left.r \leqslant n\right)$. Hinkley $(1969,1971)$ suggested erroneously that, if the estimated change point be less than $u_{2}$, then the lower confidence limit should be set as $-\infty$, and further that this would be associated with a lack of significance in the test for the existence of a change point. The error is revealed by the data under consideration; the existence of a change point near $u_{1}$ is perfectly possible, leading to the phenomenon that Hinkley (1971) ruled out. To arrive at the correct procedure, let $S\left(\gamma_{0}\right)$, for any $\gamma_{0}$, be the residual sum of squares about the least squares fit with change point $\gamma_{0}$. Then $S\left(\gamma_{0}\right)=S\left(u_{2}\right)$ for $u_{1}<\gamma_{0}$ $\leqslant u_{2}$, and hence if Hinkley's confidence intervals include $u_{2}$ they must also include the interval $\left(u_{1}, u_{2}\right)$. However, in contrast to the remarks of Hinkley (1969), points $\gamma_{0} \leqslant u_{1}$ should not be included in the confidence interval if there is known to be a significant change of slope since, on the basis of the data, the situations $\gamma_{0} \leqslant u_{1}$ and no change of slope are indistinguishable. Therefore, in the case where $u_{2}$ is acceptable as a transition point by the criterion of Hinkley: (1969), but there is a significant change of slope, we set the lower confidence limit to $u_{1}$. Rigorously the limit should be $u_{1}^{+}$since $u_{1}$ itself is not an acceptable value for the transition point.

For data on L-asparagine accumulation by organisms enriched in either fatty-acyl residue, the part of the function $\mathbf{S}(\gamma)$ on the appropriate side of the least squares estimate $\gamma$ was found to be approximately quadratic with curvature corresponding to the asymptotic formulae of Hinkley (1969). Accordingly, manipulations involving his estimated standard errors were applicable. These lead to a lower $95 \%$ confidence limit of $2.5^{\circ} \mathrm{C}$ for the increase in transition temperature for L-asparagine accumulation by linoleyl-enriched organisms relative to oleyl-enriched organisms.

\section{Accumulation of L-lysine by organisms enriched in palmitoleyl residues}

An attempt was made to examine the effect of fatty-acyl chain length of membrane phospholipids on accumulation of L-lysine, by the high-affinity system, using organisms grown in the presence of ergosterol and palmitoleic $\left(\mathrm{C}_{16: 1}\right)$ or cetoleic $\left(\mathrm{C}_{20: 1}\right)$ acid, and to compare the results with those for organisms grown in the presence of oleic acid. The phospholipid fraction from 
Table 2. Fatty-acyl composition of phospholipids and neutral lipids from S. cerevisiae NCYC 366 grown anaerobically in the presence of ergosterol and palmitoleic or oleic acid

\begin{tabular}{|c|c|c|c|c|c|c|c|}
\hline \multirow{2}{*}{$\begin{array}{l}\text { Fatty acid } \\
\text { supplement }\end{array}$} & \multirow[b]{2}{*}{ Lipid* } & \multicolumn{6}{|c|}{ Contents of residues (percentage of total) $\dagger$} \\
\hline & & $\mathrm{C}_{12: 0}$ & $\mathrm{C}_{14: 0}$ & $C_{16: 0}$ & $\mathrm{C}_{16: 1}$ & $\mathrm{C}_{18: 0}$ & $\mathrm{C}_{18: 1}$ \\
\hline \multirow[t]{4}{*}{ Palmitoleic acid } & $\mathrm{PC}$ & $2 \cdot 3$ & $2 \cdot 1$ & $33 \cdot 8$ & $47 \cdot 3$ & 14.4 & ND \\
\hline & PE & $2 \cdot 8$ & $2 \cdot 7$ & $38 \cdot 7$ & $50 \cdot 7$ & $5 \cdot 1$ & ND \\
\hline & $\mathrm{PS}+\mathrm{PI}$ & $5 \cdot 9$ & $2 \cdot 4$ & $37 \cdot 1$ & $28 \cdot 3$ & $26 \cdot 2$ & ND \\
\hline & NL & $1 \cdot 5$ & $3 \cdot 0$ & $15 \cdot 5$ & $70 \cdot 5$ & $9 \cdot 4$ & ND \\
\hline \multirow[t]{4}{*}{ Oleic acid } & PC & $1 \cdot 0$ & $6 \cdot 4$ & $25 \cdot 2$ & ND & $14 \cdot 3$ & $53 \cdot 2$ \\
\hline & $\mathrm{PE}$ & $0 \cdot 3$ & $11 \cdot 5$ & $29 \cdot 3$ & ND & $11 \cdot 7$ & $48 \cdot 0$ \\
\hline & $\mathrm{PS}+\mathrm{PI}$ & $1 \cdot 2$ & $10 \cdot 4$ & $32 \cdot 1$ & $1 \cdot 3$ & $12 \cdot 9$ & $41 \cdot 9$ \\
\hline & NL & $0 \cdot 1$ & $2 \cdot 2$ & $12 \cdot 3$ & ND & 5.9 & $79 \cdot 6$ \\
\hline
\end{tabular}

ND, Not detectable.

* Abbreviations: PC, phosphatidylcholine; PE, phosphatidylethanolamine; PS, phosphatidylserine; PI, phosphatidylinositol; NL, neutral lipids.

$\uparrow$ The values quoted are the averages of two independent analyses.

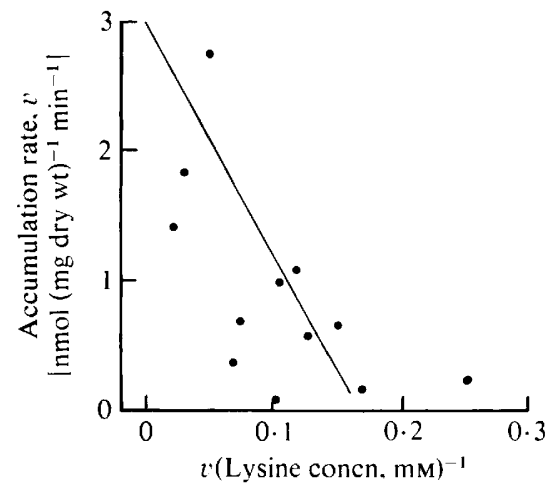

Fig. 4. Woolf-Hofstee plot for accumulation of L-lysine by S. cerevisiae NCYC 366 enriched in palmitoleyl residues. Rates of accumulation were determined as described in Methods. The line represents the relationship between points with the regression coefficient nearest unity.

organisms grown in the presence of palmitoleic acid was enriched with residues of this fatty acid to a slightly greater extent $(60.1 \%$ of total) than phospholipids from organisms grown in the presence of oleic acid, the value for which $(49.7 \%)$ was somewhat lower than that previously reported $(62.3 \%)$ for $S$. cerevisiae NCYC 366 by Thomas et al. (1978). However, the phospholipid fraction from organisms grown in the presence of cetoleic acid was enriched with cetoleyl residues to the extent of only $21.5 \%$, a low value which precluded these organisms being used to study the effect of fatty-acyl chain length on the kinetics of amino acid accumulation. In organisms grown in the presence of palmitoleic or oleic acid, phosphatidylcholine and phosphatidylethanolamine, two lipids which account for the bulk of the phospholipids in $S$. cerevisiae NCYC 366 (Hunter \& Rose, 1972), were enriched to approximately $50 \%$ of the total with residues of the fatty acid supplied in the medium (Table 2). Neutral lipids from organisms grown in the presence of either palmitoleic or oleic acid were also extensively enriched in residues of the fatty acid exogenously supplied (Table 2). Organisms grew at approximately the same rate in media containing either palmitoleic or oleic acid, although the duration of the lag phase of growth was somewhat extended in cultures supplemented with the former acid. From a Woolf-Hofstee plot for accumulation of L-lysine by the high-affinity system in organisms enriched in palmitoleyl residues (Fig. 4), $K_{\mathrm{T}}$ and $V_{\text {max }}$ values were $0.5 \times 10^{-5} \mathrm{M}$ and $1.6 \mathrm{nmol}$ (mg dry $w t)^{-1} \min ^{-1}$, respectively. 


\section{DISCUSSION}

A major finding from this study was that the kinetics of solute transport, as judged from $K_{\mathrm{T}}$ and $V_{\max }$ values, were altered in only two of the eight systems studied, when organisms enriched in oleyl residues were compared with those enriched in linoleyl residues. There are two possible explanations for identical or very similar $K_{\mathrm{T}}$ and $V_{\max }$ values for accumulation of solutes by organisms with plasma membranes enriched in oleyl rather than linoleyl residues. The proteins that make up these transport systems may be totally unaffected by the degree of unsaturation of $\mathrm{C}_{18}$ residues on phospholipids that surround them in the membrane. Alternatively, one or more of the proteins in the transport system may specifically attract phospholipid molecules that contain neither oleyl nor linoleyl residues. If so, the fatty-acyl residues on these phospholipids must be present in organisms enriched in either oleyl or linoleyl residues. The only major fattyacyl residue common to phospholipids from organisms grown anaerobically in the presence of oleic or linoleic acid is $\mathrm{C}_{16: 0}$, which accounts for $25-30 \%$ of the total residues (Thomas et al., 1978). The very similar activation energies for accumulation of L-asparagine by organisms enriched in either oleyl or linoleyl residues indicated that the transport systems operate with equal efficiency in both types of organism, being largely unaffected by the change in fatty-acyl enrichment. The small but significant increase in transition temperature when oleyl residues were replaced by linoleyl residues suggests that, in organisms enriched in the doubly unsaturated residue, one or more of the proteins in the asparagine transport system are surrounded by phospholipids with a higher melting point compared with organisms enriched in oleyl residues. This can be explained not by assuming that the transport system has a higher affinity for $\mathrm{C}_{16}$ residues in membranes enriched in linoleyl residues, but rather that it has a lower affinity for $\mathrm{C}_{18: 2}$ than for $\mathrm{C}_{18: 1}$ residues, thereby increasing the chance of proteins in the uptake system being surrounded by $\mathrm{C}_{16}$ residues.

The changes to the $K_{\mathrm{T}}$ and $V_{\max }$ values for transport of L-lysine, by both high-and low-affinity systems, caused by replacing oleyl by linoleyl residues, suggest that, in the two types of organism, different lipid molecules surround the proteins that go to make up the transport system. With the high-affinity system in oleyl-enriched organisms, the absence of a discontinuity between $5^{\circ} \mathrm{C}$ and $30^{\circ} \mathrm{C}$ suggests that over this temperature range there was no change in the state of the lipid molecules that surround proteins in the transport system. However, with organisms enriched in linoleyl residues, there was a change from a negative to a positive slope over the same temperature range. The change to a positive slope indicates a decreasing rate of L-lysine transport with increasing temperature. Assuming that the properties of the proteins that constitute the highaffinity lysine uptake system are not changed when oleyl residues in plasma-membrane phospholipids are replaced by linoleyl residues, it must be concluded that the instability in the uptake system in linoleyl-enriched organisms is attributable to the change in phospholipid composition. Implicit in this view is that the lipid annulus surrounding the proteins is made up of phospholipids containing a high proportion of the fatty-acyl residues that constituted the enrichment. Since the $V_{\max }$ value for the high-affinity system was greater in oleyl- or palmitoleyl-enriched organisms, while the activation energy was much lower in oleyl- as compared with linoleylenriched organisms, it would seem that the presence of increased fatty-acyl mobility, and therefore less tight packing in the interior of the plasma membrane, retards the rate at which lysine is moved across the membrane. On the other hand, it is clear that the nature of the fattyacyl enrichment has a more specific effect on the affinity of the high-affinity transport system for lysine, the affinity being lower in linoleyl-enriched and higher in palmitoleyl-enriched organisms, compared with those enriched in oleyl residues.

Any attempt to explain further the changes in $K_{\mathrm{T}}$ and $V_{\max }$ values for uptake of lysine by the high-affinity system, following switches in the fatty-acyl unsaturation, are complicated by three further considerations. The first of these is that lysine, when taken up by $S$. cerevisiae, is accumulated in vacuoles (Wiemken \& Dürr, 1974). It follows that, to understand the reason for changes in the kinetic values, studies will need to be made on lysine accumulation by isolated vacuoles from organisms enriched in each of the two types of residue. The second complication arises from the likelihood that the lysine uptake system is made up of several proteins, with the possibility that only certain of these proteins are affected by the fatty-acyl composition of 
surrounding phospholipids. Evidence for the possible existence of this complexity in the lysine uptake system comes from studies on uptake by $S$. cerevisiae of the closely related amino acid arginine, where periplasmically-located proteins with a high affinity for arginine as well as membrane-bound transport proteins (Opekarova et al., 1975) are involved, together with an ATPase that generates a proton gradient (Eddy, 1982). It would seem unlikely that the ATPase activity is influenced by the fatty-acyl composition of the plasma membrane, since, if one assumes that there is not a multiplicity of specific ATPases, this would have been reflected in an effect on $K_{\mathrm{T}}$ and $V_{\max }$ values for transport of asparagine and glutamine. Finally, sterols might affect the kinetics of transport systems. Enriching the plasma membrane with specific fatty-acyl residues may cause changes in the location of sterol molecules and of proteins in transport systems, thereby causing a change in $K_{\mathrm{T}}$ and $V_{\max }$ values.

Little has been reported on the stability of membrane-bound solute-transport systems in micro-organisms. The decline in arginine-transporting ability in organisms enriched in linoleyl residues might be attributable to the high fluidity in the plasma membrane in these organisms, which in turn could lead to a loss of membrane-bound proteins. Some evidence for this phenomenon comes from the finding that spheroplasts from organisms enriched in linoleyl residues leaked protein faster than spheroplasts with membranes enriched in oleyl residues (D. M. Belk $\&$ A. H. Rose, unpublished observations). Also supporting this explanation is the finding that $\alpha-$ mannosyl-transferase activities of plasma membrane preparations were more variable when the membranes were enriched in linoleyl rather than oleyl residues (L. J. Douglas, unpublished observations). It is clear, nevertheless, that plasma-membrane instability in organisms enriched in linoleyl residues has minimal physiological effects, since organisms enriched with linoleyl or oleyl residues grew at the same rate.

This work was carried out with financial assistance from the Science Research Council (U.K.) under research grant no. GR/B/25728 for which we express our thanks. We also wish to thank A. A. Eddy and G. D. Holman for valuable advice.

\section{REFERENCES}

AiyapPa, P. S. \& Lampen, J. O. (1976). Membrane associated phospholipoproteins of Bacillus licheniformis. Biochimica et biophysica acta 448, 401-410.

Alterthum, F. \& Rose, A. H. (1973). Osmotic lysis of sphaeroplasts from Saccharomyces cerevisiae grown anaerobically in media containing different unsaturated fatty acids. Journal of General Microbiology 77, 371-382.

Andreasen, A. A. \& Stier, T. J. B. (1953). Anaerobic nutrition of Saccharomyces cerevisiae. I. Ergosterol requirement for growth in a defined medium. Journal of Cellular and Comparative Physiology 41, 23-36.

Andreasen, A. A. \& StIER, T. J. B. (1954). Anaerobic nutrition of Saccharomyces cerevisiae. II. Unsaturated fatty acid requirement for growth in a defined medium. Journal of Cellular and Comparative Physiology 43, 271-281.

BEEPE, J. L. (1972). Transport alterations in a phosphatidylethanolamine-deficient mutant of Bacillus subtilis. Journal of Bacteriology 109, 939-942.

Bevers, E. M., SNOEK, G. T., Op Den KamP, J. A. F. \& VAN DeEnEN, L. L. M. (1977). Phospholipid requirement of the membrane-bound $\mathrm{Mg}^{++}$dependent ATPase in Acholeplasma laidlawii. Biochimica et biophysica acta 467, 346-356.

Borst-Pauwels, G. W. F. H. \& JAGER, S. (1969). Inhibition of phosphate and arsenate uptake in yeast by monoiodoacetate, fluoride, 2,4-dinitrophenol and acetate. Biochimica et biophysica acta 172, 399-406.
Breton, A. \& Surdin-KerJan, Y. (1977). Sulphate uptake in Saccharomyces cerevisiae: biochemical and genetic study. Journal of Bacteriology 132, 224-232.

Cox, G. S., Weissbach, H. \& Kaback, H. R. (1975). Transport in an Escherichia coli fatty acid auxotroph: a novel case of catabolite repression. Journal of Biological Chemistry 250, 4542-4548.

Cunningham, C. C. \& Hager, L. P. (1971). Crystalline pyruvate oxidase from Escherichia coli. II. Activation by phospholipids. Journal of Biological Chemistry 246, 1575-1582.

Dufour, J. P. \& Goffeau, A. (1980). Phospholipid reactivation of the purified plasma membrane A TPase of yeast. Journal of Biological Chemistry 255, 10591-10598.

DunloP, P. C. \& RoON, R. J. (1975). L-Asparaginase of Saccharomyces cerevisiae: an extracellular enzyme. Journal of Bacteriology 122, 1017-1024.

Dunlop, P. C., Meyer, G. M., Ban, D. \& Roon, R. J. (1978). Characterization of two forms of asparaginase in Saccharomyces cerevisiae. Journal of Biological Chemistry 253, 1297-1304.

EDDY, A. A. (1982). Mechanisms of solute transport in selected eukaryotic micro-organisms. Advances in Microbial Physiology 23, 1-78.

Folch, J., Lees, M. \& Sloane Stanley, G. H. (1957). A simple method for the isolation and purification of total lipids from animal tissues. Journal of Biological Chemistry 226, 497-509. 
Fuhrmann, G. F. \& Rothstein, A. (1968). The transport of $\mathrm{Zn}^{2+}, \mathrm{Co}^{2+}$ and $\mathrm{Ni}^{2+}$ into yeast cells. Biochimica et biophysica acta 163, 325-330.

GeNNIS, R. B. \& StromingeR, J. L. (1976). Activation of $\mathrm{C}_{55}$-isoprenoid alcohol phosphokinase from Staphylococcus aureus. I. Activation by phospholipids and fatty acids. Journal of Biological Chemistry 251, 1264-1269.

Hinckley, A., Mueller, E. \& Rothfield, L. (1972). Reassembly of a membrane bound multienzyme system. I. Formation of particles containing phosphatidylethanolamine, lipopolysaccharide and two glycosyltransferase enzymes. Journal of Biological Chemistry 247, 2623-2628.

HINKLEY, D. V. (1969). Inference about the intersection in two-phase regression. Biometrika 56, 495-504.

HINKLEY, D. V. (1971). Inference in two-phase regression. Journal of the American Statistical Association 66, 736-743.

HoFsteE, B. H. J. (1959). Non-inverted versus inverted plots in enzyme kinetics. Nature, London 184, 12961298.

Hossack, J. A. \& Rose, A. H. (1976). Fragility of plasma membranes in Saccharomyces cerevisiae enriched with different sterols. Journal of Bacteriology 127, 67-75.

HUNTER, K. \& Rose, A. H. (1972). Lipid composition of Saccharomyces cerevisiae as influenced by growth temperature. Biochimica et biophysica acta 260, 639653.

INOUYE, M. (1974). A three dimensional molecular assembly model of a lipoprotein from the Escherichia coli outer membrane. Proceedings of the National Academy of Sciences of the United States of America 71, 2396-2400.

Keenan, M. H. J. \& Rose, A. H. (1979). Plasma-membrane lipid unsaturation can affect the kinetics of solute accumulation by Saccharomyces cerevisiae. FEMS Microbiology Letters 6, 133-137.

KotYK, A. (1967). Properties of the sugar carrier in baker's yeast. Folia microbiologica 12, 121128.

Light, R. J., LenNaRz, W. J. \& BLOCH, K. (1962). The metabolism of hydroxystearic acids in yeast. Journal of Biological Chemistry 237, 1793-1800.

NeAL, J. L. (1972). Analysis of Michaelis kinetics for two independent. saturable membrane transport functions. Journal of Theoretical Biology 35, 113118.

Opekarova, M., Kotyk, A., Horak, J. \& KholoDENKo, V. P. (1975). Isolation and properties of an arginine-binding protein from Saccharomyces cere- visiae. European Journal of Biochemistry 59, 373376.

Peter, H. W. \& Ahlers, J. (1975). Phospholipid requirements of ATPase of Escherichia coli. Archives of Biochemistry and Biophysics 170, 169-178.

Proudlock, J. W., Wheeldon, L. W., Jollow, D. J. \& LinNANe, A. W. (1968). Role of sterols in Saccharomyces cerevisiae. Biochimica et biophysica acta 152, 434-437.

Ratcliffe, S. J., Hossack, J. A., Wheeler, G. E. \& Rose, A. H. (1973). Modification of the phospholipid composition of Saccharomyces cerevisiae induced by exogenous ethanolamine. Journal of General Microbiology 76, 445-449.

RoSE, A. H. (1977). Dialling the composition of the yeast plasma membrane. In Alcohol, Industry and Research, pp. 179-189. Edited by O. Forsander, K. Eriksson, E. Oura \& P. Jounela-Eriksson. Helsinki, Finland: Alko.

SALTON, M. R. J. \& Schor, M. T. (1974). Release and purification of Micrococcus lysodeikticus ATPase from membranes extracted with n-butanol. Biochimica et biophysica acta 345, 74-82.

SANDERMAN, H. (1978). Regulation of membrane enzymes by lipids. Biochimica et biophysica acta 515, 209-237.

SCARBorough, G. A. (1973). Transport in Neurospora. International Review of Cytology 34, 103-122.

SHERR, S. I. (1969). Phosphatidylcholine deletion from the membrane phospholipids of Neurospora crassa and its effect on lysine uptake. Bacteriological Proceedings, 120-121.

Skipski, V. P., Peterson, R. F. \& BarClay, M. (1964). Quantitative analysis of phospholipids by thin-layer chromatography. Biochemical Journal 90, 374-384.

Thomas, D. S., Hossack, J. A. \& Rose, A. H. (1978). Plasma-membrane lipid composition and ethanol tolerance in Saccharomyces cerevisiae. Archives of Microbiology 117, 239-245.

WATSON, K. \& Rose, A. H. (1980). Fatty-acyl composition of the lipids of Saccharomyces cerevisiae grown aerobically or anaerobically in media containing different fatty acids. Journal of General Microbiology 117, 225-233.

WICKERHAM, L. J. (1951). Taxonomy of yeasts. I. Techniques of classification. United States Department of Agriculture Technical Bulletin no. 1029. Washington, D.C.: U.S. Department of Agriculture.

WIEMKEN, A. \& DÜRR, M. (1974). Characterization of amino-acid pools in the vacuolar compartment of Saccharomyces cerevisiae. Archives of Microbiology 101, 45-58. 